\title{
Cardiac computed tomography angiography in the pre-operative assessment of congenital heart disease in Thailand
}

\author{
Narumol Chaosuwannakit ${ }^{1}$, Pattarapong Makarawate ${ }^{2}$, Natpalin Jantachum ${ }^{1}$ \\ ${ }^{1}$ Radiology Department, Faculty of Medicine, Khon Kaen University, Khon Kaen, Thailand \\ ${ }^{2}$ Cardiology Unit, Internal Medicine Department, Faculty of Medicine, Khon Kaen University, Khon Kaen, Thailand
}

Kardiochirurgia i Torakochirurgia Polska 2021; 18 (2): 92-99

\begin{abstract}
Introduction: Cardiac computed tomography angiography (CCTA) plays a vital role in clinical practice in evaluating patients with congenital heart disease (CHD) when the information from echocardiography is equivocal.

Aim: To test the hypothesis that CCTA has significantly value for pre-operative evaluation of congenital heart disease and practicality in the diagnosis and management of congenital heart disease patients at our tertiary care academic hospital.

Material and methods: We studied a total of 78 congenital heart disease patients (median age: 4.5 years) who had undergone CCTA during the period January 2017 to October 2018 at our tertiary care academic hospital.

Results: The results were classified as diagnostic categories, and the impact of the procedure on strategizing management was analysed. In each group, the CCTA offered an advantage and provided specific clues for surgical or interventional management. In total, the sensitivity (97.5\%), specificity (100\%), positive predictive value (100\%), negative predictive value (99.38\%), and accuracy $(99.5 \%)$ of CCTA, for which the significant findings were confirmed by surgical or cardiac catheterization, were excellent, with average exposure per CCTA study calculated at $1.41(0.36-3.28) \mathrm{mSv}$.

Conclusions: CCTA is an excellent non-invasive modality for the evaluation of congenital heart disease patients, with an important diagnostic and decision-aiding role.
\end{abstract}

Key words: congenital heart disease, cardiac computed tomography angiography, cardiac computed tomography angiography.

\section{Introduction}

Developments in surgical techniques have improved the life expectancy of patients with congenital heart disease. Thus, the population who may benefit from long-term follow-up with cross-sectional imaging is increasing [1].

Continued advances in medical imaging have provided the opportunity to diagnose cardiovascular disease using various methods that provide a wide variety of technological requirements, advantages, limitations, and costs. A well-integrated team of professionals collaborating in clinical diagnostic facilities requires sufficient implementation of each method [2,3]. Despite being the reference diagnostic method, there is a tendency towards the decreased use of diagnostic catheterization, and its use is now predominantly reserved for therapeutic decisionmaking $[4,5]$.

Traditionally, cardiologists have relied on echocardiography and conventional angiography to establish the diagnosis of congenital heart disease. Both techniques have potential limitations [6]. The echocardiographic study is op- erator dependent and limited by an acoustic window, especially in older children and adults [7]. Lung disease further complicates the quality of the echocardiographic image. Conventional angiography is an invasive procedure with its inherent risks, and during angiography, overlapping of pulmonary and systemic circulations may confuse the picture of complex anatomy [8].

Cross-sectional imaging with cardiac magnetic resonance (CMR) or cardiac computed tomography angiography (CCTA) might help overcome the limitations of conventional angiography, such as difficulties in simultaneously depicting the systemic and pulmonary vascular systems and catheter-associated complications [7, 8]. The enhanced pre-operative understanding of congenital heart disease provided by CMR and CCTA makes surgical decision-making straightforward and subsequently might improve outcome [9]. Higher spatial resolution and faster image acquisitions enable CCTA to compete with CMR as the preferred imaging technology for congenital heart disease. The 2 methods may be complementary. The intracardiac anatomy is well

Address for correspondence: Dr. Narumol Chaosuwannakit, Radiology Department, Faculty of Medicine, Khon Kaen University, Khon Kaen, Thailand, phone: 66846464640, e-mail: narumol_chao@yahoo.com Received: 13.01.2021, accepted: 16.02.2021. 
depicted by CMR, whereas CCTA provides very clear images of the great vessels [10].

CMR can precisely provide cardiac function and anatomical information that echocardiography and invasive angiography alone cannot [11, 12]. However, the disadvantages of CMR are the necessity for general anaesthesia due to longer duration image acquisition in paediatric patients, is higher cost, limited availability, and image degrading artifacts due to implanted stents and coils $[13,14]$. Thailand and other developing countries face the problem of limited resources and availability of cardiac magnetic resonance imaging (MRI). Attributable to the high gantry speed, excellent spatial and temporal resolution, state-of-the-art ultrafast CT scanners have significantly improved the diagnostic performance of CCTA. Ultrafast CCTA can obtain volume acquisition of the entire heart and coronary arteries within 3-4 seconds, with excellent temporal and spatial resolution [15]. The reconstructed images, such as maximal intensity projection (MIP) and 3D volume rendering technique (VRT) images, are of pronounced benefit for the preoperative preparation and post-operative assessment of congenital heart disease patients. Tachycardia and arrhythmias are the major limitations of CCTA. Nevertheless, these limiting factors have partly been overcome by dual-source CT (DSCT) scanners. Somatom definition Flash (Siemens Healthcare, Forchheim, Germany) is a modern ultra-fast CT scanner that can scan the entire heart in a fraction of the heartbeat, and the total scanning period is 0.25 to $0.27 \mathrm{sec}$ onds [16].

CCTA can be considered the imaging modality of choice for certain disorders, such as assessing major aortopulmonary collateral arteries (MAPCAS), pulmonary atresia, and abnormal thoracic vascular structures [6].

\section{Aim}

The present study was conducted to accentuate the usefulness of CCTA in assessing congenital cardiovascular diseases across a broad spectrum of pathologic structures.

\section{Material and methods}

We studied a total of 78 congenital heart disease patients who had undergone cardiac CTA (CCTA) in our tertiary care academic hospital from January 2017 to October 2018, with complete medical records. Echocardiography is the first-line modality of choice in all patients with congenital heart disease. CCTA imaging was done only in patients for whom echocardiography or angiography was not a completely informative or mandatory confirmation of echocardiography findings. The indication for CCTA was pre-operative evaluation of congenital heart disease patients, which is considered an appropriate indication for CCTA, based on the Society of Cardiovascular computed tomography's expert consensus document [17]. The CCTA exclusion criteria included kidney dysfunction and a history of allergic reactions to the iodinated contrast agent. The present study was accepted by the Faculty of Medicine Eth- ics Committee, Khon Kaen University, Khon Kaen, Thailand, research number HE611608.

\section{Dual-source CCTA scanning protocol}

Sedation, intubation, and adverse procedural occasions were determined from medical records. Almost all patients could complete CCTA without general anaesthesia. Imaging was accomplished using a second-generation dualsource CT scanner (Somatom Definition; Siemens Healthcare, Forchheim, Germany). The radiation dose is kept to a minimum by appropriately reducing the voltage and tube current. We used $80 \mathrm{kV}$ and $80 \mathrm{mAs}, 80 \mathrm{kV}$ and $100 \mathrm{mAs}$, and $100 \mathrm{kV}$ and $120 \mathrm{mAs}$, respectively, for children weighing less than $10 \mathrm{~kg}, 10-19 \mathrm{~kg}$, and $20-30 \mathrm{~kg}$. Automated dose regulation strategies such as CARE dose 4D (Siemens Healthcare) are used to reduce radiation [16]. A $1.5 \mathrm{ml} / \mathrm{kg}$ bolus of iodinated contrast medium for a dual-head power injector at a rate of $1.5-2.0 \mathrm{ml} / \mathrm{s}$ for a 22-gauge cannula, $3.0 \mathrm{ml} / \mathrm{s}$ for a 20-gauge cannula, and $4.0-5.0 \mathrm{ml} / \mathrm{s}$ for an 18-gauge cannula, followed by a $10-20 \mathrm{ml}$ saline flush at the same rate as the contrast injection, were administered. A power injector is routinely used to ensure a continuous and regular flow rate. The entire volume of the heart and great vessels was covered in approximately 5 seconds during one breath-hold. Patients were scanned in the supine position [16].

\section{Cardiac CT angiography imaging analysis}

All acquired CCTA images were transferred to a dedicated 3D post-processing workstation, and the image analysis was accomplished by an experienced cardiovascular radiologist with 10 years of experience in examining cardiac CTA by using the maximum intensity projections (MIPs), curved multiplanar reformations (cMPRs), and volume rendering technique (VRT). All image data were evaluated using Syngovia software (Siemens Healthcare). MIP and CMPR are mainly used to evaluate curved structures - for example, major aortopulmonary collateral arteries (MAPCAs) and coronary arteries. Minimum-intensity projection (MinIP) is used to evaluate the lung parenchyma and airways. VRT is applied for demonstrated complex anatomy.

\section{Parameters for radiation dose}

The imaging sequence, CT dose-volume index (mGy), scan dose-length product $(\mathrm{mG} y-\mathrm{cm})$, scan dose-length product ( $\mathrm{mGy}-\mathrm{cm}$, phantom $16 \mathrm{~cm}$ ), scan length, and tube current were documented in each study. Individual scans and cumulative procedural dose-length products were documented in $\mathrm{mGy}-\mathrm{cm}$.

\section{Radiation dose estimation}

To assess the radiation exposure, a procedural doselength product was used. By calculating the dose-length product with the standard chest conversion factor provided as the scan dose-length product to 0.014 , an unadjusted ra- 
diation dose in millisievert (mSv) was determined [18, 19]. Conversion factors were further determined as per the recommendations from previous studies $[19,20]$.

\section{Ethical declarations}

This study was reviewed and approved by the local Ethics Committee of Khon Kaen University, Thailand and was registered under reference number HE611608. All methods were performed in accordance with the relevant guidelines and regulations.

\section{Statistical analysis}

Continuous variables were described as the median. Analyses were conducted using version 19.0 of SPSS (SPSS Inc., Chicago, Illinois). Furthermore, taking the surgical and/ or cardiac catheterization results as the standard reference, the sensitivity, specificity, and diagnostic accuracy of CCTA for cardiovascular abnormalities was appraised.

Table I. Pulmonary artery evaluation (Group 1)

\begin{tabular}{|c|c|c|}
\hline Indication (n) & CCTA findings ( $n$ ) & $\begin{array}{c}\text { Impact on } \\
\text { management }(n)\end{array}$ \\
\hline $\begin{array}{l}\text { - Pulmonary atre- } \\
\text { sia with VSD (11) }\end{array}$ & $\begin{array}{l}\text { - Confluent pulmo- } \\
\text { nary arteries (5) } \\
\text { - Non-confluent pul- } \\
\text { monary arteries (6) } \\
\text { - Major aortopul- } \\
\text { monary collateral } \\
\text { arteries (10) } \\
\text { - PDA (1) }\end{array}$ & $\begin{array}{l}\text { - Unifocalization (1) } \\
\text { - Modified Blalock- } \\
\text { Taussig shunt (4) } \\
\text { - Conservative } \\
\text { treatment (6) }\end{array}$ \\
\hline $\begin{array}{l}\text { - Monitor growth } \\
\text { of pulmonary } \\
\text { arteries after the } \\
\text { procedure (3) }\end{array}$ & $\begin{array}{l}\text { - Adequate growth } \\
\text { without discrete } \\
\text { stenosis (1) } \\
\text { - Inadequate growth } \\
\text { (2) }\end{array}$ & $\begin{array}{l}\text { - Surgery augmenta- } \\
\text { tion of the pulmo- } \\
\text { nary artery (2) } \\
\text { - Conservative } \\
\text { treatment (1) }\end{array}$ \\
\hline
\end{tabular}

Table III. Coronary artery anomalies (Group 3)

\begin{tabular}{|c|c|c|}
\hline Indication ( $n$ ) & CCTA findings $(n)$ & $\begin{array}{l}\text { Impact on } \\
\text { management ( } n)\end{array}$ \\
\hline $\begin{array}{l}\text { - Coronary-cameral } \\
\text { fistula (5) }\end{array}$ & $\begin{array}{l}\text { - Coronary artery } \\
\text { fistulas from LAD to } \\
\text { RV and PA (5) }\end{array}$ & $\begin{array}{l}\text { - Surgical closure } \\
\text { fistula (3) } \\
\text { - Conservative } \\
\text { treatment (2) }\end{array}$ \\
\hline $\begin{array}{l}\text { - Anomalous origin } \\
\text { of the coronary ar- } \\
\text { tery, inter-arterial } \\
\text { type (10) }\end{array}$ & $\begin{array}{l}\text { - Anomalous origin } \\
\text { of RCA from the left } \\
\text { sinus of Valsalva (9) } \\
\text { - Anomalous origin of } \\
\text { LCA from the right } \\
\text { sinus of Valsalva (1) }\end{array}$ & $\begin{array}{l}\text { - Reimplantation of } \\
\text { coronary artery (3) } \\
\text { - Conservative } \\
\text { treatment (7) }\end{array}$ \\
\hline $\begin{array}{l}\text { - Anomalous } \\
\text { of RCA (6) }\end{array}$ & $\begin{array}{l}\text { - } \text { Retroaortic } \\
\text { course }(6)\end{array}$ & $\begin{array}{l}\text { - Conservative } \\
\text { treatment (6) }\end{array}$ \\
\hline $\begin{array}{l}\text { - Single coronary } \\
\text { artery (4) }\end{array}$ & $\begin{array}{l}\text { - Type L-II-C (1) } \\
\text { - Type R-IIA (1) } \\
\text { - Type L-I (2) }\end{array}$ & $\begin{array}{l}\text { - Conservative } \\
\text { treatment (4) }\end{array}$ \\
\hline $\begin{array}{l}\text { - Anomalous left } \\
\text { coronary artery } \\
\text { from the pulmo- } \\
\text { nary artery (2) }\end{array}$ & $\begin{array}{l}\text { - Anomalous left } \\
\text { coronary artery } \\
\text { from the pulmonary } \\
\text { artery (ALCAPA) (2) }\end{array}$ & $\begin{array}{l}\text { - Total surgical } \\
\text { correction (2) }\end{array}$ \\
\hline
\end{tabular}

\section{Results}

A total of 78 congenital heart disease patients who underwent cardiac computed tomography angiography between January 2017 and October 2018 for pre-operative assessment and had complete medical records were enrolled in the study. Each patient could be classified into more than 1 group because of several findings. The study participants' ages ranged from 9 days to 74 years (median: 4.5 years). The male: female ratio was 1.16 . The number of males was 42 (53.85\%) and females 36 (46.15\%). Patients' weights ranged from 2.7 to $68 \mathrm{~kg}$ (median: $15.6 \mathrm{~kg}$ ). The average DLP was $1.41(0.36-3.28) \mathrm{mSv}$. There were no procedure-related complications. The results were classified as diagnostic categories (groups 1-5; Tables I-V), and the impact of the procedure on strategizing management was analysed. The common indication for CCTA in the current study was the requirement to evaluate pulmonary artery anatomy and major aortopulmonary collateral arteries (MAPCAs) in

Table II. Aortic anomalies (Group 2)

\begin{tabular}{|c|c|c|}
\hline Indication (n) & CCTA findings $(n)$ & $\begin{array}{c}\text { Impact on } \\
\text { management }(n)\end{array}$ \\
\hline $\begin{array}{l}\text { - Coarctation of } \\
\text { the aorta (5) }\end{array}$ & $\begin{array}{l}\text { - Coarctation of aorta } \\
\text { preductal type (3) } \\
\text { - Juxtaductal type (2) } \\
\text { - Persistent left SVC (1) }\end{array}$ & $\begin{array}{l}\text { - Surgical repair of } \\
\text { coarctation (4) } \\
\text { - Conservative } \\
\text { treatment (1) }\end{array}$ \\
\hline $\begin{array}{l}\text { - Truncus } \\
\text { arteriosus (2) }\end{array}$ & $\begin{array}{l}\text { - Single great artery } \\
\text { arising from the heart } \\
\text { and bifurcation into } \\
\text { the aorta and MPA (1) } \\
\text { - Single great artery } \\
\text { arising from the heart } \\
\text { and the pulmonary } \\
\text { arteries arising } \\
\text { separately from the } \\
\text { posterior portion } \\
\text { of the truncus (1) } \\
\text { - Subtruncal VSD (2) }\end{array}$ & $\begin{array}{l}\text { - Total surgical } \\
\text { correction (2) }\end{array}$ \\
\hline
\end{tabular}

Table IV. Heterotaxy syndrome (Group 4)

\begin{tabular}{|c|c|c|}
\hline Indication ( $n$ ) & CCTA findings ( $n$ ) & $\begin{array}{c}\text { Impact on } \\
\text { management }(n)\end{array}$ \\
\hline $\begin{array}{l}\text { - Right } \\
\text { isomerism (2) }\end{array}$ & $\begin{array}{l}\text { - } \text { Single atrium (2) } \\
\text { - Complete atrioventricu- } \\
\text { lar septal defect (1) } \\
\text { - Absent spleen (2) } \\
\text { - Right-sided aortic arch (1) } \\
\text { - TAPVR (2) } \\
\text { - Pulmonary stenosis (2) } \\
\text { - DORV (1) }\end{array}$ & $\begin{array}{l}\text { - Central shunt (1) } \\
\text { - Total surgical } \\
\text { correction (1) }\end{array}$ \\
\hline $\begin{array}{l}\text { - Left } \\
\text { isomerism (3) }\end{array}$ & $\begin{array}{l}\text { - Interrupted IVC with } \\
\text { azygos continuation (2) } \\
\text { - } \text { DORV (1) } \\
\text { - } \text { ASD (3) } \\
\text { - VSD (2) } \\
\text { - Polysplenia (3) } \\
\text { - TAPVR (1) } \\
\text { - Pulmonary stenosis (2) } \\
\text { - Tracheal bronchus (1) } \\
\text { - } \text { Bilateral SVC (1) }\end{array}$ & $\begin{array}{l}\text { - Rerouting of the } \\
\text { pulmonary vein (1) } \\
\text { - Total surgical } \\
\text { correction (1) } \\
\text { - Conservative } \\
\text { treatment (1) }\end{array}$ \\
\hline
\end{tabular}


the pulmonary atresia with ventricular septal defect patients $(n=11)$ (Figure 1$)$. Five cases were considered as the confluence of pulmonary arteries. Three cases with confluent pulmonary arteries proceeded to palliative surgical procedure. Of the 6 cases with non-confluent pulmonary arteries, 1 proceeded to unifocalization, and 1 underwent a palliative surgical procedure. Simultaneously, 6 confluent and non-confluent pulmonary arteries had conservative management because their anatomy made surgical intervention excessively difficult. In 3 cases, the growth of pulmonary arteries was observed after a palliative surgical procedure (systemic to pulmonary shunt). The findings are shown in Table I.

In the group of aortic anomalies (Table II), there were 5 cases of coarctation of the aorta. Three cases were preductal type, and 2 cases were juxtaductal type (Figure 2). Of 5 cases of coarctation of the aorta, 4 proceeded to repair coarctation of the aorta surgically, and 1 case was conservative treatment. There were 2 cases of truncus arteriosus, 1 case of single great artery arising from the heart and bifurcation into the aorta and MPA (Collett and Edwards classification type I), and 1 case of a single great artery arising from the heart and the pulmonary arteries arising separately from the posterior portion of the truncus (Collett and Edwards classification type II), and subtruncal VSD was also found in both cases.

In the group of coronary artery anomalies (Table III), there were 27 cases. Nine of them had anomalous origin of the RCA from the left sinus of Valsalva (Figure 3), of which 3 cases had undergone surgical reimplantation of the coronary artery, and 7 cases had conservative treatment. Five cases had coronary artery fistula, 6 were cases of anomalous RCA with retroaortic course, 4 were cases of single coronary artery, and 2 were cases of anomalous left coronary artery from the pulmonary artery (ALCAPA).

There were 5 cases of heterotaxy syndrome group (Table IV). One case of right isomerism (Figure 4) underwent a central shunt, and another case underwent total surgical correction. Three cases of left isomerism were identified, and 1 of them proceeded to rerouting of the pulmonary vein, 1 case underwent total surgical correction, and another case had conservative treatment.

Miscellaneous group (Table $V$ ) includes the following: 19 cases of tetralogy of Fallot (TOF), 1 case of pentalogy of Fallot, 21 cases of atrial septal defect (ASD), 15 cases of ventricular septal defect (VSD), 7 cases of double outlet right ventricle (DORV), and 1 case of patent ductus arteriosus (PDA). Fourteen cases of TOF had total surgical correction or palliative modified Blalock-Taussig shunt. Eight cases of ASD had surgical ASD closure. Five cases of VSD had surgical VSD closure or planning of surgical closure, whereas 10 cases had conservative treatment. All cases of DORV had a palliative surgical procedure or planned surgical correction, and all cases of PDA had undergone PDA closure.

In total, the sensitivity (97.5\%; 95\% Cl: 91.26-99.7\%), specificity $(100 \%$; $95 \% \mathrm{Cl}$ : $95.32-100 \%)$, positive predictive value (100\%; 95\% Cl: 98.7-100\%), negative predictive
Table V. Miscellaneous (Group 5)

\begin{tabular}{|c|c|c|}
\hline Indication ( $n$ ) & CCTA findings $(n)$ & $\begin{array}{l}\text { Impact on } \\
\text { management }(n)\end{array}$ \\
\hline • TOF (19) & $\begin{array}{l}\text { - } \text { Pulmonary valve } \\
\text { stenosis (6) } \\
\text { - Confluent pulmonary } \\
\text { arteries (17) } \\
\text { - } \text { MAPCAs (3) } \\
\text { - PDA (2) } \\
\text { - PFO (2) }\end{array}$ & $\begin{array}{l}\text { - Total surgical } \\
\text { correction (6) } \\
\text { - Modified Blalock- } \\
\text { Taussig shunt (8) } \\
\text { - Conservative } \\
\text { treatment (5) }\end{array}$ \\
\hline $\begin{array}{l}\text { - Pentalogy } \\
\text { of Fallot (1) }\end{array}$ & $\begin{array}{l}\text { - TOF with ASD, PDA, } \\
\text { MAPCAs (1) }\end{array}$ & $\begin{array}{l}\text { - Total surgical } \\
\text { correction (1) }\end{array}$ \\
\hline - ASD (21) & $\begin{array}{l}\text { - Secundum type (7) } \\
\text { - Primum type (5) } \\
\text { - Sinus venosus type (8) } \\
\text { - Combined type veno- } \\
\text { sus and secundum (1) }\end{array}$ & $\begin{array}{l}\text { - ASD closure (8) } \\
\text { - Conservative } \\
\text { treatment (13) }\end{array}$ \\
\hline • VSD (15) & $\begin{array}{l}\text { - Perimembranous } \\
\text { type (7) } \\
\text { - Muscular type (1) } \\
\text { - Inlet type (3) } \\
\text { - Outlet type (4) }\end{array}$ & $\begin{array}{l}\text { - VSD closure (4) } \\
\text { - Planning of surgical } \\
\text { closure (1) } \\
\text { - Conservative } \\
\text { treatment (10) }\end{array}$ \\
\hline - DORV (7) & $\begin{array}{l}\text { - DORV with perimem- } \\
\text { branous VSD (3) } \\
\text { - DORV with large inlet } \\
\text { type VSD (1) } \\
\text { - DORV with subaortic } \\
\text { VSD (3) }\end{array}$ & $\begin{array}{l}\text { - Palliative surgical } \\
\text { procedure (5) } \\
\text { - Planning of total } \\
\text { surgical } \\
\text { correction (2) }\end{array}$ \\
\hline - PDA (3) & $\begin{array}{c}\text { - Patent ductus } \\
\text { arteriosus (3) }\end{array}$ & $\begin{array}{l}\text { - Device closure PDA (2) } \\
\text { - Surgical closure PDA (1) }\end{array}$ \\
\hline
\end{tabular}

value (99.38\%; 95\% Cl: 97.6-99.84\%), and accuracy (98.6\%; 95\% Cl: $96.74-99.99 \%)$ ) of CCTA, the major findings of which were confirmed by surgical and/or cardiac catheterization, were excellent.

\section{Discussion}

The novel generation of CT has transformed the approach to non-invasive evaluation of congenital heart disease. A previous study appraised the application of 3D CT scanning for congenital heart disease, concluding that it had become an invaluable diagnostic and decision-aiding tool, a complement to echocardiography, and often a substitute for invasive diagnostic angiography [21].

The current study attempted to examine the specific advantage of CCTA for a diversity of anatomic abnormalities across the spectrum of congenital heart disease. For the evaluation of pulmonary arteries, CCTA was particularly worthwhile in demonstrating confluence or discontinuity of the pulmonary major aortopulmonary collateral arteries (MAPCAs) (Figure 1). It assisted in the selection of surgical techniques and in evaluating the growth of the pulmonary artery after the procedure. Therefore, CCTA assisted the management decision based (on the regularly questioned of the pulmonary artery anatomy) arteries. For aortic anomalies, CCTA precisely identified the coarctation site, the severity of narrowing, and the associated diseases (Figure 2). CCTA in paediatrics is hindered by high heart rate affecting cardiac motion artifacts. Nevertheless, in selected 

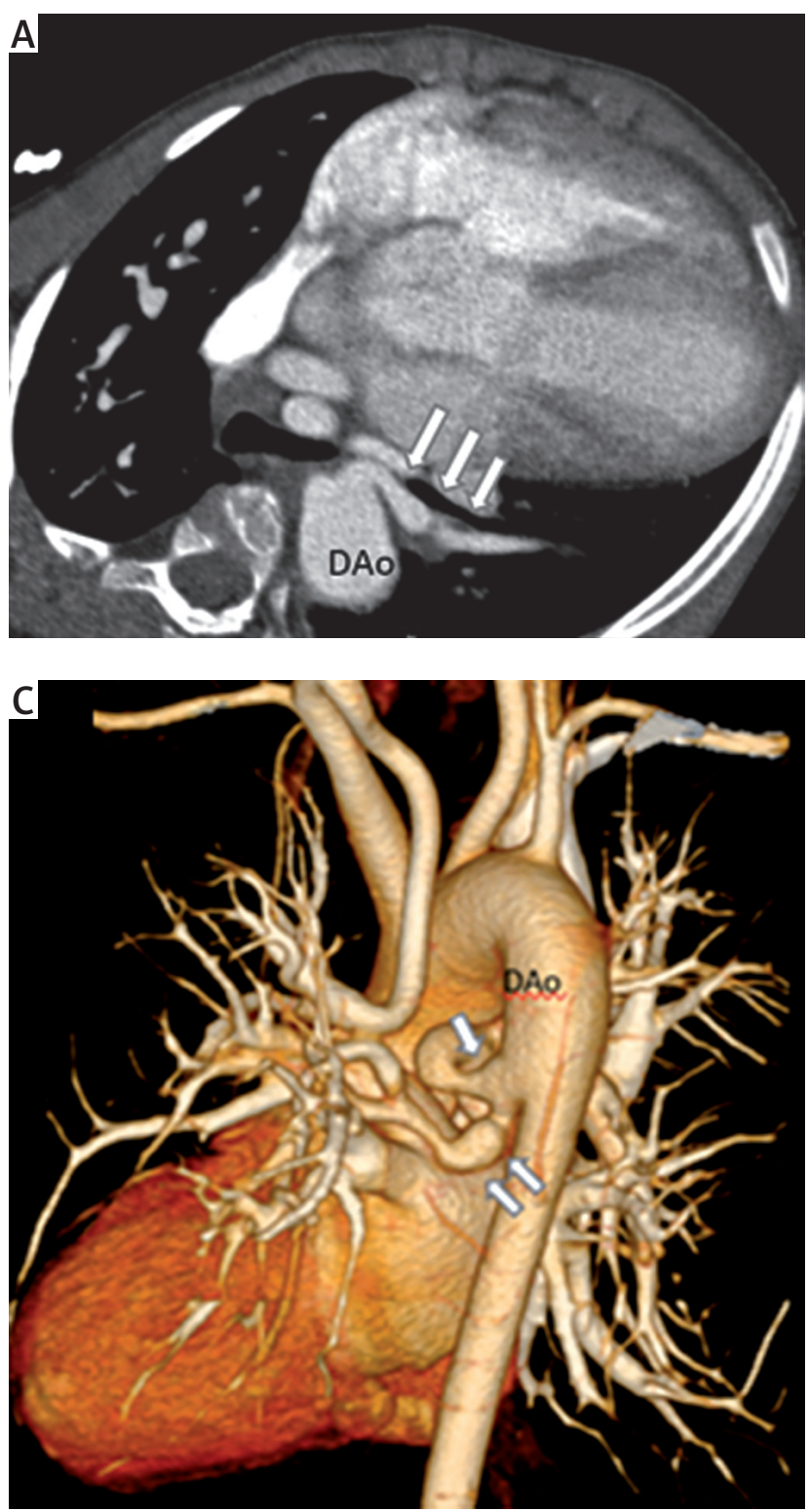

cases, this limitation did not preclude demonstration of the origin and course of coronary arteries in the present study. CCTA determined the origin and course of the coronary artery precisely in an 8-year-old boy with an anomalous origin of the right coronary artery from the left sinus of Valsalva (Figure 3). Furthermore, CCTA was less invasive than conventional angiography. In particular, CCTA was valuable for visceral heterotaxy, establishing the assorted range of abnormalities in various structures in addition to cardiac abnormalities (Figure 4). Consequently, CCTA assisted in categorizing pulmonary situs, visceral malposition, asplenia, and polysplenia. With the exception of CMR, no other imaging modality demonstrates all the anatomic details of heterotaxy in a single study. The intracardiac anatomy, systemic and pulmonary venous connection, and extracardiac vessels were well defined and validated by surgical findings. CCTA was extremely valuable in illustrating the eparterial or hyparterial position of bronchi in heterotaxy

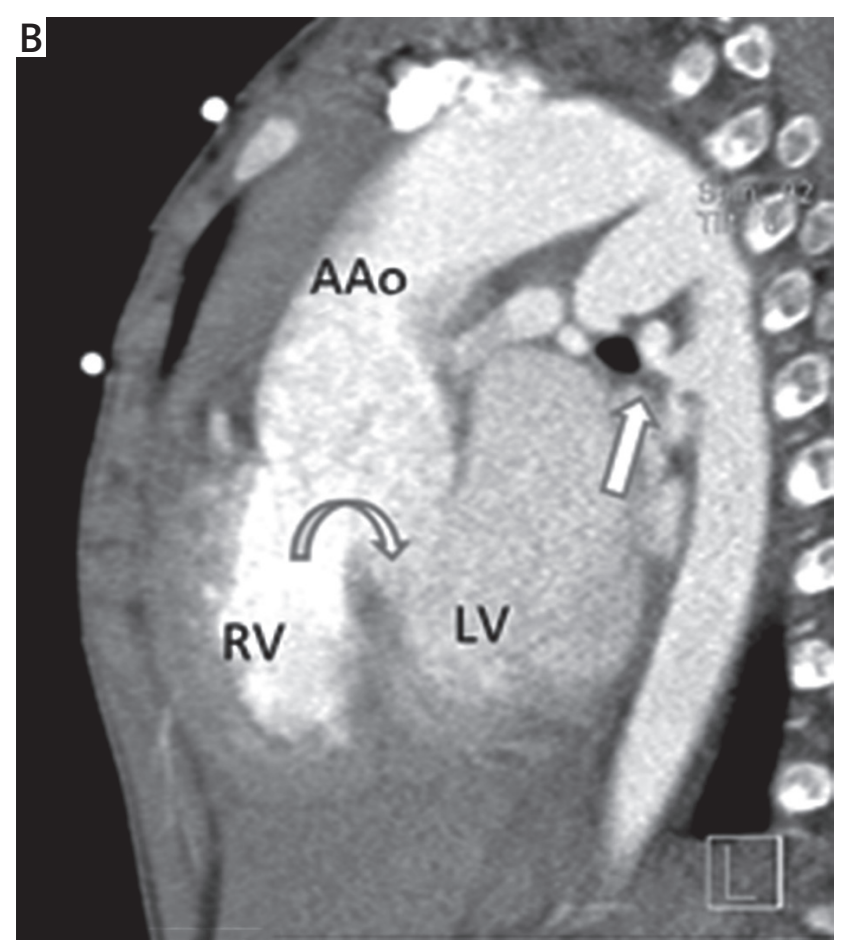

Figure 1. A 7-year-old boy with PA with VSD. Cardiac computed tomography angiography axial view (A), sagittal view (B), and volume rendering image $(\mathbf{C})$ demonstrate the major aortopulmonary collateral arteries (MAPCAs) from descending thoracic aorta (white arrows) and revealed ventricular septal defect (B: curved arrow) PA - pulmonary atresia, VSD - ventricular septal defect, AAo - ascending thoracic aorta, DAo - descending thoracic aorta, RV - right ventricle, LV - left ventricle.

syndrome in the present study (Figure 4), similarly to the previous study, which disclosed the effectiveness of CT for assessing tracheobronchial anomalies in children with congenital heart disease [22].

A major concern in CCTA is radiation exposure. Previous studies revealed that the average radiation exposure per study is diverse, ranging from less than 1 to $28.4 \mathrm{mSv}$, notwithstanding the short period of scanning [13-16, 23, 24]. The present study tried to minimize radiation exposure by following the as-low-as-reasonably-achievable (ALARA) principle. The average exposure per CCTA study was calculated at $1.41(0.36-3.28) \mathrm{mSv}$ in the present study compared to natural background radiation for 6 months. A previous study advised that after preliminary valuation with echocardiography, CCTA could possibly substitute invasive diagnostic catheterization for supplementary anatomic clarification in neonates [25]. The current study revealed that this conception could be extended to all age groups 

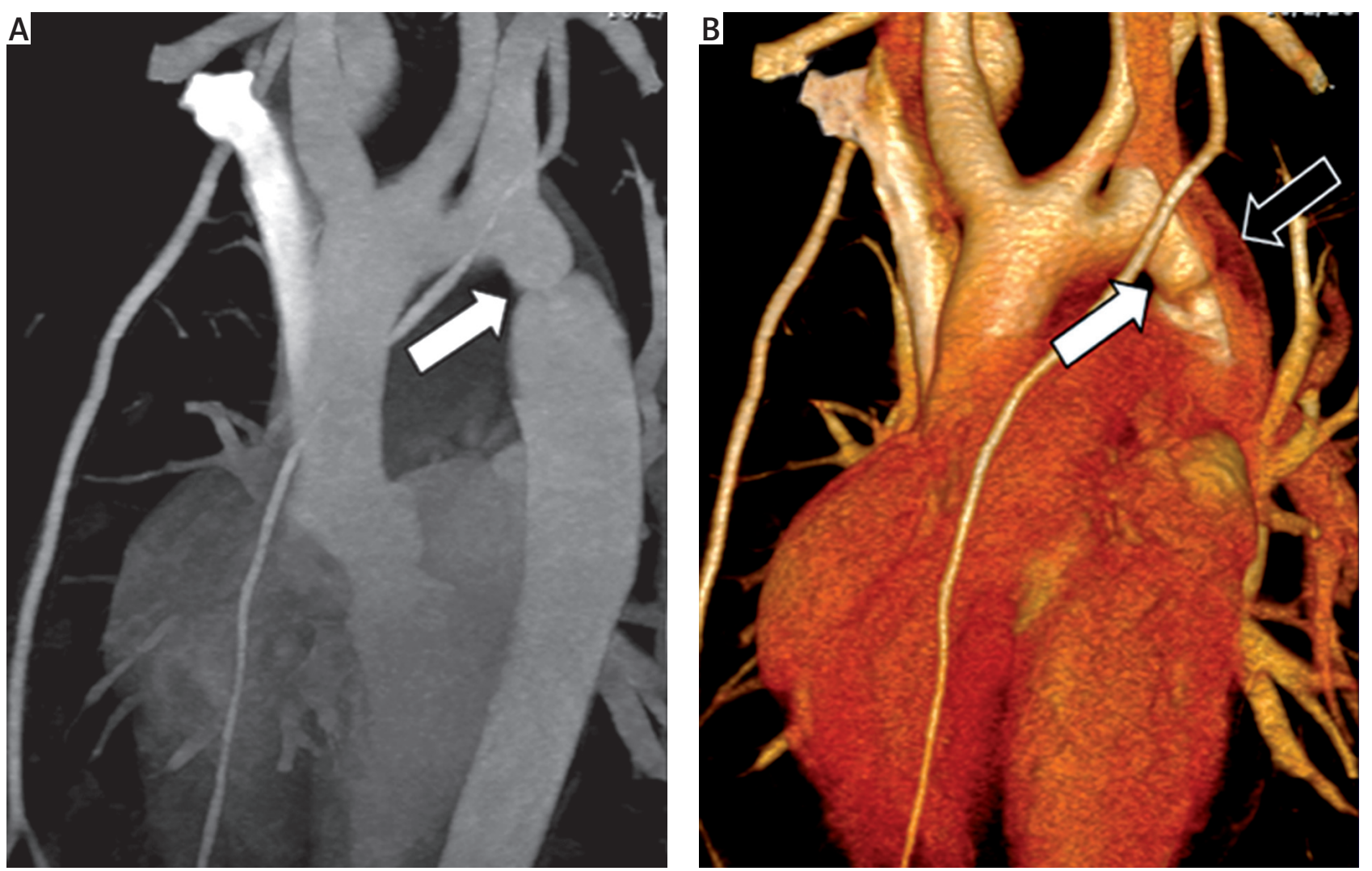

Figure 2. A 10-year-old girl with coarctation of the aorta. Cardiac computed tomography angiography sagittal oblique (A) and volume rendering image (B) shows the abnormal small diameter of aortic isthmus (A and B: white arrows) and demonstrates persistent left SVC (B: black arrow)
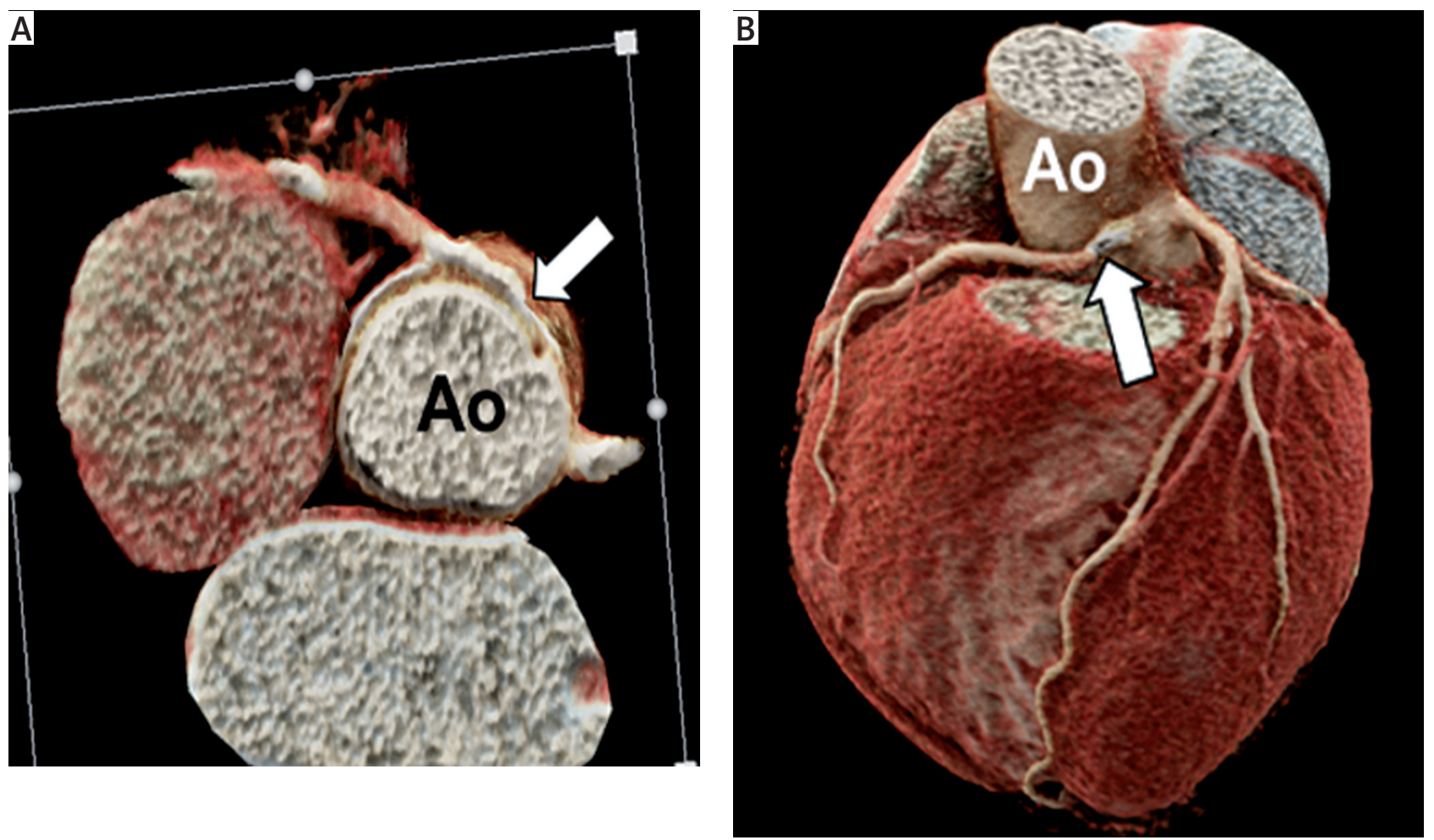

Figure 3. An 8-year-old boy with a right coronary artery from the left sinus of Valsalva, inter-arterial type. Cardiac computed tomography angiography demonstrates the right coronary artery arising from the left sinus of Valsalva and course between aorta and pulmonary artery (inter-arterial type) (A and B: white arrows)

Ao - aorta, PA - pulmonary artery. 

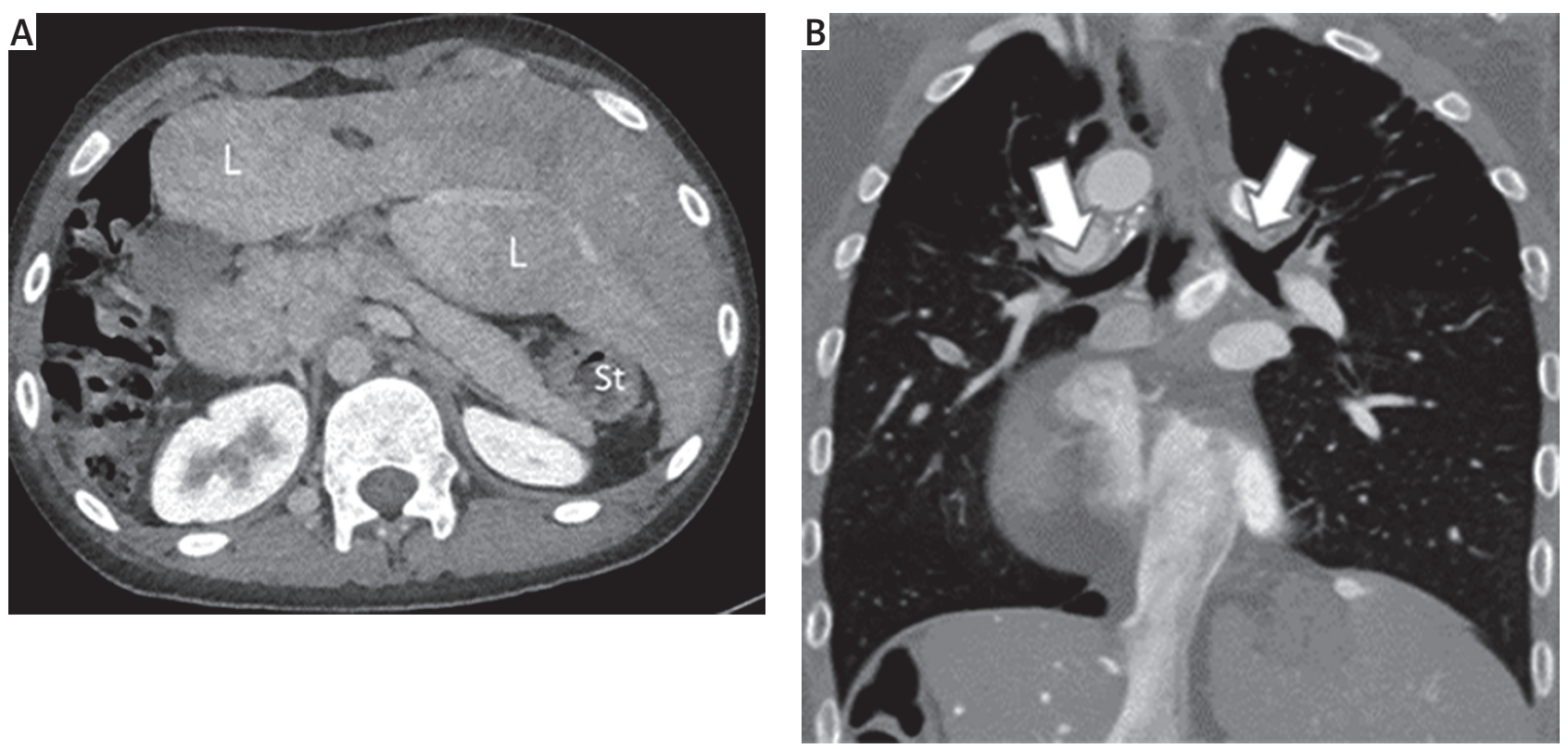

Figure 4. A 13-year-old boy with right isomerism. Cardiac computed tomography angiography axial (A) and coronal view (B) demonstrate transverse liver (L) and absence of spleen (asplenia) (A) and bilateral eparterial bronchus (B: white arrows)

$\mathrm{L}$ - liver, St - stomach.

for congenital heart disease. Ever since the introduction of CCTA, the number of diagnostic invasive catheterization procedures has decreased dramatically at our institution. Invasive cardiac catheterization has been required only for cases in which physiological information has been essential. CMR does not require ionizing radiation and can provide a range of useful information. Nevertheless, CCTA may be preferable to CMR because of the simplicity of the investigation and the rapidity of image acquisition [21]. Because CCTA has a shorter scan time and has fewer sedation necessities than CMR, it can be accomplished more easily in an unstable patient who needs intensive monitoring and care, and it avoids the associated procedural risks. CCTA has better spatial resolution; consequently, it is superior at identifying the coronary arteries and small collateral vessels. The presence of an implanted pacemaker or defibrillator, other contraindication to CMR, or vascular stents generally cause more artifacts with CMR than CCTA.

There are some limitations of the present study. Firstly, due to retrospective design, missing data were inevitable. Secondly, this study was not intended as a head-to-head comparison of CCTA and other modalities of imaging. We have not attempted to compare CCTA with its major competitor, CMR. Finally, our findings reflect a single-centre experience, and the generalizability of the current results is limited.

\section{Conclusions}

Advances in CT scanners and CCTA techniques have resulted in superior image quality with increased use of CCTA for assessing congenital heart disease patients. DSCT with novel technology is the foremost innovation in cardiovascular imaging, with superior temporal resolution and the abil- ity to diminish radiation exposure. The present study has revealed the importance and decision-aiding role of CCTA in assessing congenital heart disease, with excellent diagnostic performance, particularly for answering questions not determined by echocardiography. Anatomical information attained from CCTA might be prudently used to limit the number of views acquired using invasive catheterization, and it might be a substitute diagnostic method to invasive cardiac catheterization, and hence be valuable for planning surgery or interventional cardiac catheterization. Finally, CCTA may then be valuable in terms of reducing global radiation exposure in congenital heart disease patients.

\section{Acknowledgments}

The authors would like to thank Department of Surgery, Department of Paediatrics, Department of Radiology, and Faculty of Medicine, Khon Kaen University, for their support. We sincerely appreciate Dr. Seehapong Phetcharat and Dr. Chawalit Wongbuddha for their substantial contribution to the present study. We would like to acknowledge Prof. Yukifumi Nawa for editing the manuscript via Publication Clinic KKU, Thailand.

\section{Disclosure}

The authors report no conflict of interest.

\section{References}

1. Marelli AJ, Mackie AS, Ionescu-Ittu R, Rahme E, Pilote L. Congenital heart disease in the general population changing prevalence and age distribution. Circulation 2007; 115: 163-172.

2. Warnes CA, Williams RG, Bashore TM, Child JS, Connolly HEM, Dearani JA, Del Nido P, Fasules JW, Graham Jr TP, Hijazi ZM, Hunt SA, King ME, Landzberg MJ, Miner PD, Radford MJ, Walsh EP, Webb GD. ACC/AHA 2008 Guide- 
lines for the Management of Adults with Congenital Heart Disease: a report of the American College of Cardiology/American Heart Association Task Force on Practice Guidelines (writing committee to develop guidelines on the management of adults with congenital heart disease). Circulation 2008; 118: e714-e833.

3. Thomas JD, Zoghbi WA, Beller GA, Bonow RO, Budoff MJ, Cerqueira MD, Creager MA, Douglas PS, Fuster V, Garcia MJ, Holmes Jr DR, Manning WJ, Pohost GM, Ryan TJ, Van Decker WA, Wiegers SE, American College of CArdiology Foundation (ACCF); American Heart Association (AHA); American College of Physicians (ACP) Task Force on Clinical Competence and Training. ACCF 2008 Training Statement on Multimodality Noninvasive Cardiovascular Imaging A Report of the American College of Cardiology Foundation/American Heart Association/American College of Physicians Task Force on Clinical Competence and Training Developed in Collaboration With the American Society of Echocardiography, the American Society of Nuclear Cardiology, the Society of Cardiovascular Computed Tomography, the Society for Cardiovascular Magnetic Resonance, and the Society for Vascular Medicine. J Am Coll Cardiol 2009; 53: 125-146.

4. Fratz S, Chung T, Greil GF, Samyn MM, Taylor AM, Valsangiacomo Buechel ER, Yoo SJ, Powell AJ. Guidelines and protocols for cardiovascular magnetic resonance in children and adults with congenital heart disease: SCMR expert consensus group on congenital heart disease.J Cardiovasc Magn Reson 2013; 15: 51.

5. Tomasian A, Malik S, Shamsa K, Krishnam MS. Congenital heart diseases: post-operative appearance on multi-detector CT-a pictorial essay. Eur Radiol 2009; 19: 2941-2949.

6. Leschka S, Oechslin E, Husmann L, Desbiolles L, Marincek B, Genoni M, Prętre R, Jenni R, Wildermuth S, Alkadhi H. Pre-and post-operative evaluation of congenital heart disease in children and adults with 64-section CT. Radiographics 2007; 27: 829-846.

7. Samyn MM. A review of the complementary information available with cardiac magnetic resonance imaging and multislice computed tomography (CT) during the study of congenital heart disease. Int J Cardiovasc Imaging 2004; 20: $569-567$

8. Han BK, Rigsby CK, Hlavacek A, Leipsic J, Nicol ED, Siegel MJ, Bardo D, Abbara S, Ghoshhajra B, Lesser JR, Raman S, Crean AM, Society of Cardiovascular Computed T, Society of Pediatric R and North American Society of Cardiac I. Computed Tomography Imaging in Patients with Congenital Heart Disease Part I: Rationale and Utility. An Expert Consensus Document of the Society of Cardiovascular Computed Tomography (SCCT): Endorsed by the Society of Pediatric Radiology (SPR) and the North American Society of Cardiac Imaging (NASCI). J Cardiovasc Comput Tomogr 2015; 9: 475-492.

9. Han BK, Rigsby CK, Leipsic J, Bardo D, Abbara S, Ghoshhajra B, Lesser JR, Raman SV, Crean AM, Nicol ED, Siegel MJ, Hlavacek A, Society of Cardiovascular Computed T, Society of Pediatric R and North American Society of Cardiac I. Computed Tomography Imaging in Patients with Congenital Heart Disease, Part 2: Technical Recommendations. An Expert Consensus Document of the Society of Cardiovascular Computed Tomography (SCCT): Endorsed by the Society of Pediatric Radiology (SPR) and the North American Society of Cardiac Imaging (NASCI). J Cardiovasc Comput Tomogr 2015; 9: 493-513.

10. Boxt LM. Magnetic resonance and computed tomographic evaluation of congenital heart disease. J Magn Reson Imaging 2004; 19: 827-847.

11. Johnson JT, Molina KM, McFadden M, Minich LA, Menon SC. Yield of cardiac magnetic resonance imaging as an adjunct to echocardiography in young infants with congenital heart disease. Pediatr Cardiol 2014; 35: 1067-1071.
12. Kilner PJ, Geva T, Kaemmerer H, Trindade PT, Schwitter J, Webb GD. Recommendations for cardiovascular magnetic resonance in adults with congenital heart disease from the respective working groups of the European Society of Cardiology. Eur Heart J 2010; 31: 794-805.

13. Taylor AM. Cardiac imaging: MR or CT? Which to use when. Pediatr Radiol 2008; 38: 433-438.

14. Enaba MM, Hasan DI, Alsowey AM, Elsayed H. Multidetector computed tomography (CT) in evaluation of congenital cyanotic heart diseases. Pol J Radiol 2017; 82: 645-659

15. Rajiiah P, Saboo SS, Abbara S. Role of CT in congenital heart disease. Curr Treat Options Cardiovasc Med 2017; 19: 6-10.

16. Booij R, Dijkshoorn ML, Straten MV, Pleassis FA, Budde RP, Moelker A, Kres tin GP, Ouhlous M. Cardiovascular imaging in pediatric patients using dualsource CT. J Cardiovasc Comput Tomogr 2016; 10: 13-21.

17. Taylor AJ, Cerqueira M, Hodgson JM, Mark D, Min J, O'Gara P, Rubin GD. ACCF/SCCT/ACR/AHA/ASE/ASNC/NASCI/SCAI/SCMR 2010 appropriate use criteria for cardiac computed tomography. A report of the American College of Cardiology Foundation Appropriate Use Criteria Task Force, the Society of Cardiovascular Computed Tomography, the American College of Radiology, the American Heart Association, the American Society of Echocardiography, the American Society of Nuclear Cardiology, the North American Society for Cardiovascular Imaging, the Society for Cardiovascular Angiography and Interventions, and the Society for Cardiovascular Magnetic Resonance. J Am Coll Cardiol 2010; 56: 1864-1894.

18. Halliburton SS, Abbara S, Chen MY, Gentry R, Mahesh M, Raff GL, Shaw LJ, Hausleiter J, Society of Cardiovascular Computed Tomography. SCCT guidelines on radiation dose and dose-optimization strategies in cardiovascular CT. J Cardiovasc Comput Tomogr 2011; 5: 198-224.

19. Trattner S, Halliburton S, Thompson CM, Xu Y, Chelliah A, Jambawalikar SR, Peng B, Peters MR, Jacobs JE, Ghesani M, Jang JJ, Al-Khalidi H, Einstein AJ. Cardiac-specific conversion factors to estimate radiation effective dose from dose-length product in computed tomography. JACC Cardiovasc Imaging 2018; 11: 64-74.

20. Christner JA, Kofler JM, McCollough CH. Estimating effective dose for CT using dose-length product compared with using organ dose: consequences of adopting International Commission on Radiological Protection publication 103 or dual-energy scanning. Am J Roentgenol 2010; 194: 881-889.

21. Ou P, Celermajer DS, Calcagni G, Brunelle F, Bonnet D, Sidi D. Three-dimensional CT scanning: a new diagnostic modality in congenital heart disease. Heart 2007; 93: 908-913.

22. Chen SJ, Lee WJ, Wang JK, Wu MH, Chang Cl, Liu KL, Chiu IS, Chen HY, Su CT, Li YW. Usefulness of three dimensional electron beam computed tomography for evaluating tracheobronchial anomalies in children with congenital heart disease. Am J Cardiol 2007; 92: 483-486.

23. Chandran A, Fricker FJ, Schowengerdt KO, Cumming WA, Saidi A, Spencer CT, Paolillo J, Samyn MM. An institutional review of the value of computed tomographic angiography in the diagnosis of congenital cardiac malformations. Cardiol Young 2005; 15: 47-51.

24. Jelnin V, Co J, Muneer B, Swaminathan B, Toska S, Ruiz CE. Three-dimensional $\mathrm{CT}$ angiography for patients with congenital heart disease: scanning protocol for pediatric patients. Catheter Cardiovasc Interv 2006; 67: 120-126.

25. Lee T, Tsai IC, Fu YC, Jan SL, Wang CC, Chang Y, Chen MC. Using multidetectorrow $\mathrm{CT}$ in neonates with complex congenital heart disease to replace diagnostic cardiac catheterization for anatomical investigation: initial experiences in technical and clinical feasibility. Pediatric Radiol 2006; 36: 1273-1282. 